\title{
sciendo
}

\section{Anthropometric and Motor Characteristics of South African National Level Female Soccer Players}

\author{
by \\ Marc Jon Booysen ${ }^{1}$, Philippe Jean-Luc Gradidge ${ }^{1}$, Demitri Constantinou ${ }^{1}$
}

\begin{abstract}
Data regarding anthropometric and motor characteristics of elite national level female soccer players are scarce. Determining these characteristics may likely assist in evaluating the specificity of current training programmes, identify players who might lack specific qualities deemed critical for the successful execution of their tactical roles, and benchmark norms for developing future playing talent. Therefore, the aims of this study were to describe anthropometric and motor characteristics of South African national level female soccer players $(n=37)$ and determine possible differences with regard to their playing position. The following measurements and tests were performed: anthropometry (body mass index and sum-of-skinfolds), the countermovement jump, sprints (10 m, $20 \mathrm{~m}$ and $40 \mathrm{~m})$, upper body muscle endurance (push-ups) and the Yo-Yo Intermittent Recovery Test - level 1. One-way analysis of variance revealed few differences in the main outcome variables. Fischer Least Significant Difference (LSD) showed that strikers had a greater body mass index than midfielders and defenders (both $p=0.04$ ) and goalkeepers were heavier than defenders $(p=0.02)$. Goalkeepers were slower than strikers and defenders over $10 \mathrm{~m}(p=0.01 ; p=0.03)$ and $20 \mathrm{~m}(p=$ $0.001 ; p=0.01)$. Midfielders were slower than strikers over $20 \mathrm{~m}(p=0.02)$, and with strikers and defenders over $40 \mathrm{~m}$ (both $p=0.04)$. Defenders performed better than goalkeepers in the upper body muscle endurance test $(p=0.02)$. In conclusion, both strikers and defenders require speed to win ball possession, which may explain their fast sprint times. However, the similarity of certain motor characteristics across playing positions may suggest that conditioning coaches train players similarly, irrespective of their tactical position. The authors suggest that South African fitness professionals, particularly at a club level, develop physical conditioning programs specific to each field position. Furthermore, fitness assessments should occur on a continuous basis and comparisons should be made with existing normative data in order to guide the development of players over the course of their careers.
\end{abstract}

Key words: soccer, speed, Yo-Yo Intermittent recovery test, elite, females, African.

\section{Introduction}

Female participation in soccer has grown in popularity in recent years with over 29 million players worldwide (Martínez-Lagunas et al., 2014). As with male soccer, female soccer has become more competitive, with players continuously striving to improve their performance at international tournaments (Martínez-Lagunas et al., 2014). Yet, despite this increase in professionalism, data on anthropometric and motor characteristics of female players in terms of their playing positions are lacking (Ingebrigtsen et al., 2011). Assessments of this nature are important for evaluating the physical preparedness of a team to contend at international competitions and for the development of normative data (Datson et al., 2014; Reilly et al., 2000).

Soccer is a challenging sport that requires a high level of physical fitness at the elite level (Krustrup et al., 2005; Manson et al., 2014). For instance, elite female soccer players cover an average distance of $10.3 \mathrm{~km}$ during the $90 \mathrm{~min}$

\footnotetext{
1 - Centre for Exercise Science and Sports Medicine (CESSM), School of Therapeutic Sciences, Faculty of Health Sciences, University of the Witwatersrand, Johannesburg, South Africa.
} 
period of a match (Krustrup et al., 2005) which is respectively 23 and $46 \%$ more distance compared to elite female athletes competing in netball and field hockey (Davidson and Trewartha, 2008; McGuinness et al., 2017). The intermittent nature of the game utilizes all major energy systems (Stolen et al., 2005), which can result in acute fatigue, and consequently a reduced capability in technical performance (Hoff, 2005).

Aerobic fitness tests such as the Yo-Yo intermittent running test Level 1 (Yo-Yo IR1) allow for the assessment of athlete's ability to recover from strenuous activity (Krustrup et al., 2005). At elite levels, female soccer players are reported to achieve an average of $1302 \mathrm{~m}$ in the Yo-Yo IR1 (Krustrup et al., 2005; Mujika et al., 2009). Anaerobic attributes such as sprinting speed and explosive jumping, are also important determinants of success in soccer matches, as they contribute to winning possession of the ball (Reilly et al., 2000) and goal scoring (Faude et al., 2012). Unsurprisingly, elite female soccer players are significantly faster than their non-elite counterparts (Manson et al., 2014). Individual studies show that the countermovement jump (CMJ) heights of elite female players (Castagna and Castellini, 2013; Mujika et al., 2009) are similar to those of elite female athletes participating in other field-based team sports (Gabbett, 2007; Ohya et al., 2015). In terms of anthropometry, female soccer players are lighter, shorter in height and have lower body fat percentages compared to volleyball and basketball players (Santos et al., 2014) and are comparable in body size to field hockey players (Ohya et al., 2015). One could argue that this is due to soccer players covering more ground in a match compared to court-based athletes. Furthermore, soccer players with lower body fat percentages perform better in game-specific endurance tests than those with higher levels (Mujika et al., 2009), indicating the importance of optimal body composition.

The development of position-specific physical fitness is important to consider, particularly as players have assigned roles within a team. This concept has been qualified in motion analysis of elite female soccer players, highlighting that forwards participate in more sprint activity during the match than defenders or midfielders (Vescovi, 2012). However, findings seem to be inconsistent when comparing anthropometric and motor characteristics across the different playing positions at elite female soccer players. While some studies have shown differences between certain positions (Bradley et al., 2014; Haugen et al., 2012; Sedano et al., 2009), other studies have reported similarity between playing positions (Ingebrigtsen et al., 2011; Milanovic et al., 2012). This may be due to female players receiving similar training despite their positional differences (Martínez-Lagunas et al., 2014). This could have negative implications as the similarity of their training methods can lead to homogeneity in physical adaptations and result in less than optimal performance in the various positions. Furthermore, the assessment of anthropometry is also important as it would indicate whether specific physical qualities such as body mass and height are required for performance in certain positions at international level. For instance, in male soccer, defenders and goalkeepers are heavier and taller in order to fulfill their position roles such a protecting the goal area (Reilly et al., 2000; Sporis et al., 2007).

Knowledge of the anthropometric and motor characteristics can assist in evaluating the specificity of current training programmes, identify players who might lack specific qualities deemed critical for the successful execution of their tactical roles, and benchmark norms for developing future playing talent (Datson et al., 2014; Ingebrigtsen et al., 2011). Without this critical information one cannot make accurate recommendations for future player development, specifically within an African context. Consequently, the aims of this study were to describe the anthropometric and motor characteristics of national level female soccer players from South Africa and determine possible differences with regard to their playing position.

\section{Methods}

\section{Participants}

Data were collected during a training camp prior to an international tournament on thirty-seven $(n=37)$ South African female soccer players from the national senior squad. The squad players represented various semi-professional clubs across the country and were selected by the national selection committee to represent South Africa. At the time of testing the national squad 
was entering an intense training period and players were assumed to be at or near optimal levels of physical fitness. Participants included the outfield playing positions \{defenders $(\mathrm{n}=11)$, midfielders $(\mathrm{n}=11)$, strikers $(\mathrm{n}=9)\}$, and the goalkeeper position $(n=6)$. The study was approved by the University of the Witwatersrand's Human Research Ethics Committee (Medical). A combined information sheet and an informed consent form were given and explained to players on the day of the original testing prior to commencement, and included consent for the use of data for research purposes. All participants were free of injury and illness at the time of testing.

\section{Procedures}

Testing followed systematic order and commenced with a 10-min dynamic warm-up performed by all participants. Then anthropometric measurements and physical performance tests which included the CMJ, sprints, local muscle endurance, and lastly a specific endurance running test (Harman, 2008), were completed. Correct technique and performance criteria were explained and demonstrated to the participants before the start of each test. Sprint and endurance running tests were performed by the participants on a soccer pitch in cleats. Tests were conducted in Johannesburg, South Africa at an altitude of $\pm 1750 \mathrm{~m}$ above sea level.

\section{Anthropometric testing}

All anthropometric measurements were collected with participants wearing training shorts and sports brassiere. Body mass was measured with participants standing barefoot on an electronic scale (SECA 877: B5 5QB, Birmingham, UK) and recorded in kilograms $(\mathrm{kg})$ to the nearest $0.01 \mathrm{~kg}$. Body height $(\mathrm{m})$ was measured using a wall mounted stadiometer (SECA 206: B5 5QB, Birmingham, UK) with participants standing barefoot in an upright position with the head in the Frankfort plane. Measurements were rounded to the nearest 0.01 $\mathrm{m}$. The body mass index (BMI, $\mathrm{kg} \cdot \mathrm{m}^{-2}$ ) was calculated according to Thompson et al. (2010). Skin fold measurements were taken at six sites on the right side of the body using the Slim Guide C120R skin fold calipers. The anatomical sites used were: triceps, subscapular, iliac crest, abdominal, quadriceps and medial calf (Garrido-
Chamorro et al., 2012; Mujika et al., 2009). The average of two measurements was used for data analysis. The sum of the skinfolds was measured in millimeters $(\mathrm{mm})$. Girth measurements were taken according to the American College of Sports Medicine's (ACSM) guidelines (Thompson et al., 2010) at the waist and hip using a standard tape measure placed parallel with the ground. The waist circumference was measured between the umbilicus and the xiphoid process at the narrowest point. The hip circumference was measured at the greatest posterior protuberance of the hip and proximal thigh. A waist-to-hip ratio was then calculated.

\section{Power}

Power was assessed using the CMJ test, commonly used in soccer testing (Castagna and Castellini, 2013; Wisløff et al., 2004), which is a valid and reliable test of lower extremity power (Markovic et al., 2004). Vertical jump height was recorded to the nearest millimetre using a flighttime based jump mat (Fusion Sport Smart Jump mat, Fusion Sport, 2 Henley ST, Coopers Plains, QLD, 4108, Australia) and Smart Jump PDA (HP IPAQ 112, Hewlett Packard Company, Palo Alto, CA 94304). At the start of the test participants stood in the centre of the jump mat. From this position they were instructed to descend, bending the knees and hips to a self-selected depth (McLellan et al., 2011) and then without a pause, jump for maximal height. Participants were allowed to swing their arms freely to increase force generation and were instructed that their knees should be fully extended during the flight phase (Markovic et al., 2004). The participants performed two trials with a $1 \mathrm{~min}$ rest period between jumps (Wisløff et al., 2004). The trial with the greatest vertical jump height was recorded and used for further analysis.

\section{Sprint testing}

Participants' maximal sprinting speed was tested over 20 and $40 \mathrm{~m}$ for goalkeepers and infield players, respectively. Times (in ms) were recorded by four infra-red timing gates (Fusion Sport Smart Speed, Fusion Sport, 2 Henley ST, Coopers Plains, QLD, 4108, Australia) positioned at the start and at 10, 20 and $40 \mathrm{~m}$. Each participant carried out two maximal trials separated by five minutes of rest (Wisløff et al., 2004). At the start of each trial, the participants positioned their lead foot on a line $15 \mathrm{~cm}$ behind 
the first timing gate. Each test started from a static standing position, with the time recorded from when the participants intercepted the first timing gate (Wisløff et al., 2004). The fastest time recorded over 20 and $40 \mathrm{~m}$ was used for data analysis.

\section{Upper body muscle endurance}

The maximal number of full body pushups that could be performed in $60 \mathrm{~s}$ was performed to test the upper body muscular endurance of the participants. At the start of the test, participants assumed the standard push-up start position (Harman, 2008) with hands placed shoulder-width apart, elbows and knees fully extended and the upper and lower body held in a straight line (Harman, 2008). For a repetition to be counted, participants had to lower themselves until their upper arms were parallel with the floor and then return to the start position. Participants were only allowed to rest in the start position i.e. could not rest with their knees on the ground. The maximum number of repetitions that could be achieved in $60 \mathrm{~s}$ was recorded.

\section{Intermittent running capacity}

Intermittent running capacity was tested using the Yo-Yo intermittent recovery test 1 (YoYo IR1) (Bitworks Design, Cheltenham, UK, Team Beep Test $20 \mathrm{~m}$, version 4:0). The Yo-Yo IR1 is a valid and reliable test for determining aerobic capacity in soccer players (Krustrup et al., 2003). At the sound of an audible beep, participants were required to reach a set of cones $20 \mathrm{~m}$ away and return to the starting line before the next beep. The interval between the beeps was progressively shortened at the start of each new stage, thus forcing players to increase their running speed. Between each $40 \mathrm{~m}$ running bout the participants were given a $10 \mathrm{~s}$ active rest in which they jogged $5 \mathrm{~m}$ out and back to the starting position. Participants were asked to stop the test if they twice failed to complete the two shuttles in the time period designated by the beeps. The total distance covered by the participant was recorded for further analysis.

\section{Statistical analysis}

Statistica Version 13.2 (StatSoft, Tulsa, OK, USA) was used for all statistical analyses. Numerical values were expressed as a mean with standard deviations (SD). Comparisons between playing positions were made using analysis of variance (ANOVA). Post hoc analysis was performed using the Fisher Least Significant Difference (LSD) test. Significance was set at the level of $p<0.05$.

\section{Results}

Goalkeepers were heavier than defenders $(p=$ $0.02)$, whereas strikers had a greater BMI than midfielders and defenders (both $p=0.04$ ). No differences were found between positions for sum-of-skinfolds or the waist-to-hip ratio (both $p$ $=0.58$ ) (Table 1). Goalkeepers were significantly slower than strikers and defenders in both the 10 $\mathrm{m}(p=0.01, p=0.03)$ and $20 \mathrm{~m}(p=0.001 ; p=0.01)$ sprints. Midfielders were significantly slower than strikers over the $20 \mathrm{~m}$ sprint $(p=0.02)$, and both strikers and defenders over the $40 \mathrm{~m}$ sprint (both $p=0.04$ ) (Figure 1). Defenders performed better in the upper body muscle endurance test than goalkeepers $(p=0.02)$. No significant differences were observed for the CMJ $(p=0.55)$, and the YoYo IR1 ( $p=0.61)$ tests.

\section{Discussion}

The participation of females in soccer is becoming increasingly popular across the world, yet research investigating the characteristics of national level female players from sub-Saharan Africa is sparse. Therefore the aim of the study was to describe the anthropometric and motor characteristics of South African national female soccer players and determine differences between various playing positions. The results showed significant differences in sprint times, with goalkeepers slower than strikers and defenders over 10 and $20 \mathrm{~m}$ sprints. Furthermore, midfielders were slower than strikers over $20 \mathrm{~m}$ and slower than both strikers and defenders over $40 \mathrm{~m}$. Few other differences in anthropometric and motor outcomes were observed, specifically between outfield playing positions.

\section{Anthropometry}

The results are consistent with other studies which show similarity amongst national level female soccer players with regard to anthropometry (Milanovic et al., 2012; Sporis et al., 2007). Interestingly, strikers weighed more relative to their body height than midfielders and defenders, which could possibly be attributed to greater muscle mass. 


\begin{tabular}{|c|c|c|c|c|}
\hline \multicolumn{5}{|c|}{$\begin{array}{c}\text { Table } 1 \\
\text { Anthropometric and physical performance values of South African } \\
\text { national level female soccer players }\end{array}$} \\
\hline Variable & $\begin{array}{c}\text { Goalkeepers } \\
(n=6)\end{array}$ & $\begin{array}{c}\text { Defenders } \\
(\mathrm{n}=11)\end{array}$ & $\begin{array}{l}\text { Midfielders } \\
(\mathrm{n}=11)\end{array}$ & $\begin{array}{c}\text { Strikers } \\
(\mathrm{n}=9)\end{array}$ \\
\hline Age (years) & $22.5 \pm 4.93$ & $22.1 \pm 2.81$ & $23.2 \pm 2.68$ & $23.0 \pm 4.39$ \\
\hline Mass (kg) & $65.2 \pm 8.65^{*}$ & $57.2 \pm 3.11$ & $59.2 \pm 7.55$ & $61.3 \pm 5.99$ \\
\hline Stature $(\mathrm{m})$ & $1.67 \pm 0.04$ & $1.62 \pm 0.04$ & $1.65 \pm 0.07$ & $1.62 \pm 0.06$ \\
\hline BMI (kg.) & $23.3 \pm 2.56$ & $21.9 \pm 0.85$ & $21.8 \pm 1.55$ & $23.3 \pm 1.54 \dagger$ \\
\hline Waist-to-hip ratio & $0.74 \pm 0.03$ & $0.75 \pm 0.04$ & $0.73 \pm 0.04$ & $0.74 \pm 0.03$ \\
\hline Skinfolds (mm) & $89.0 \pm 5.23$ & $77.4 \pm 10.2$ & $81.1 \pm 25.1$ & $78.3 \pm 17.5$ \\
\hline CMJ height (cm) & $35.1 \pm 4.96$ & $36.9 \pm 4.54$ & $37.2 \pm 5.36$ & $39.1 \pm 5.40$ \\
\hline Sprints (s) - $10 \mathrm{~m}$ & $1.95 \pm 0.13 \ddagger$ & $1.85 \pm 0.09$ & $1.89 \pm 0.09$ & $1.81 \pm 0.07$ \\
\hline$-20 \mathrm{~m}$ & $3.41 \pm 0.17 \ddagger$ & $3.20 \pm 0.12$ & $3.30 \pm 0.16 \S$ & $3.15 \pm 0.09$ \\
\hline$-40 \mathrm{~m}$ & - & $5.73 \pm 0.21$ & $5.96 \pm 0.33 \mathbb{I}$ & $5.71 \pm 0.19$ \\
\hline Pushups - reps in $60 \mathrm{~s}$ & $26.7 \pm 11.3$ & $40.2 \pm 14.01 \mathrm{I}$ & $35.4 \pm 9.6$ & $35.1 \pm 7.42$ \\
\hline Yo-Yo IR1 (m) & $887 \pm 325$ & $1167 \pm 470$ & $1055 \pm 439$ & $1067 \pm 348$ \\
\hline \multicolumn{5}{|c|}{$\begin{array}{r}\text { Skinfolds = Sum-of-skinfolds, Yo-Yo IR1 }(m)=Y o \text {-Yo Intermittent Running Test-Level } 1(m) ; \\
\text { *Significantly greater than defenders }(p<0.05) ; \\
\text { +Siginificantly greater than defenders and midfielders }(p<0.05) ; \\
\text { ‡Significantly slower than strikers and defenders }(p<0.05) ; \\
\text { §Significantly slower than strikers }(p<0.05) ; \\
\text { II Significantly slower than strikers and defenders }(p<0.05) ; \\
\text { IISignificantly greater than goalkeepers }(p<0.05)\end{array}$} \\
\hline
\end{tabular}

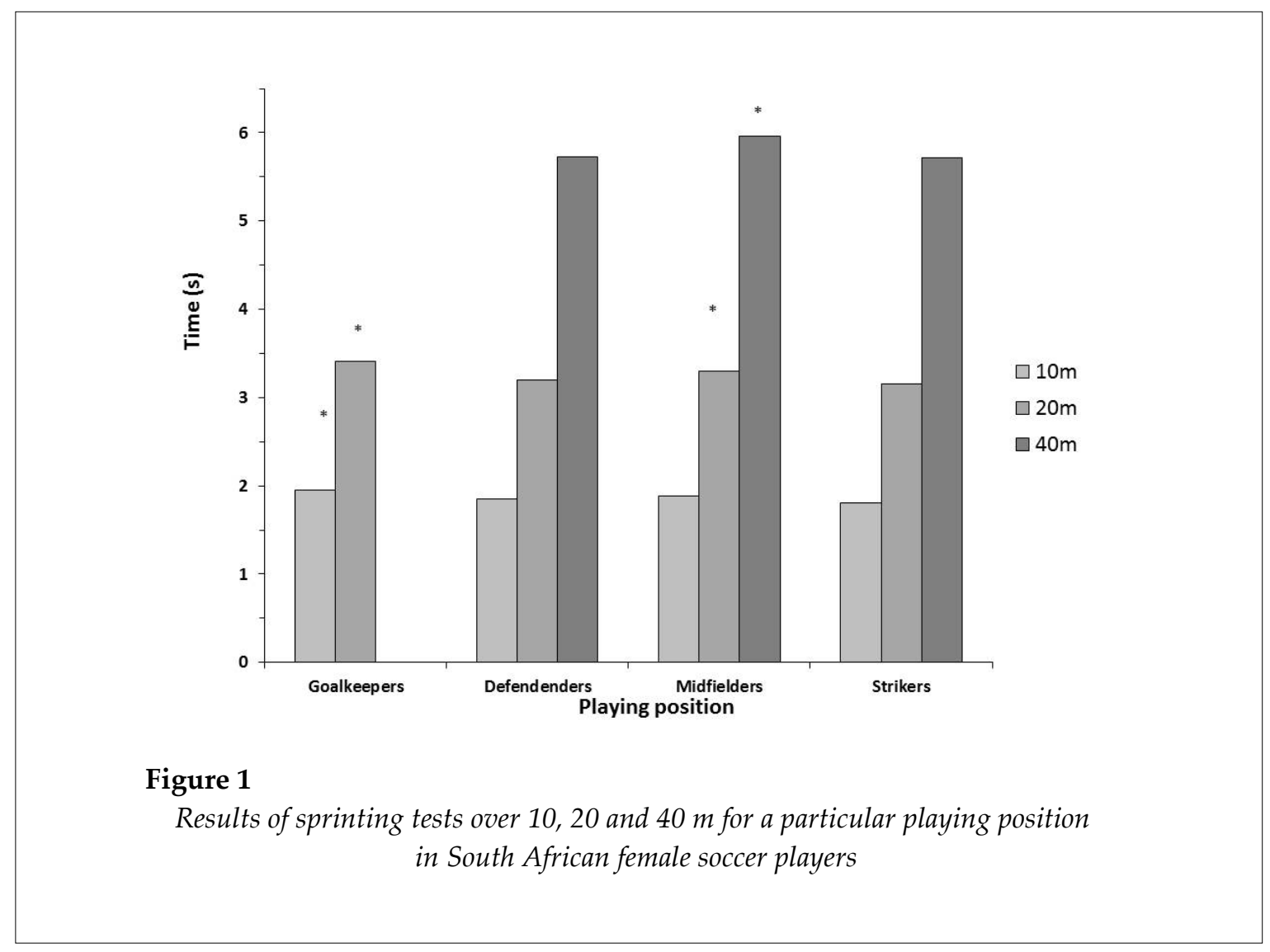


Furthermore, goalkeepers had higher mean body mass, stature and sum-of-skinfold values than infield playing positions, supporting the findings of Sedano et al. (2009) and similar to those observed in elite male soccer players (Clark, 2007; Sporis et al., 2009). A possible reason for this is that goalkeepers run less distance in the game, expending less energy, whereas infield players tend to be lighter and leaner in order to cover greater match distances. Additionally, greater height would be advantageous for goalkeepers who need to protect the goal mouth (Reilly et al., 2000). The skinfold measurements of the South African outfield players (mean: $84.1 \mathrm{~mm}$ ) fall within a range of means for elite female soccer players reported by Mujika et al. (2009) and Garrido-Chamorro et al. (2012) of 74.4 and 100 $\mathrm{mm}$, respectively. Additionally, mean body mass $(60.1 \mathrm{~kg})$ and height $(1.64 \mathrm{~m})$ of the participants in the current study fall within the values reported in a review of international female players (range for mass: $56.8-64.9 \mathrm{~kg}$ and range for height: 1.61$1.70 \mathrm{~m}$ ) (Datson et al., 2014).

\section{Power}

No significant differences were found between playing positions for CMJ height confirming the findings in other female national soccer players' populations (Haugen et al., 2012; Sedano et al., 2009). Furthermore, the mean CMJ heights reported for the South African national females $(37 \mathrm{~cm})$ are within a mean range of CMJ heights $(30-38 \mathrm{~cm})$ which have been reported for elite female soccer players (Castagna and Castellini, 2013; Haugen et al., 2012; Mujika et al., 2009). Power is crucial for optimal sprint and agility performance in female players (McFarland et al., 2016). Therefore, it was not surprising that the strikers had the fastest sprint times, as they had the highest values of all four positions in the CMJ test.

Sprints

Goalkeepers were significantly slower than strikers and defenders for both $10 \mathrm{~m}$ and 20 $\mathrm{m}$ sprints. Goalkeepers do not require the ability to sprint as fast as strikers or defenders, as the majority of their game activity is located around the goal box. The activities of strikers and defenders on the other hand include many high speed sprints in order to win possession of the ball. Furthermore, strikers were faster than midfielders over $20 \mathrm{~m}$ and $40 \mathrm{~m}$ sprint distances, which is similar to the findings of Haugen et al. (2012). Strikers not only perform more sprints during a match, but their sprint distances are greater than those of midfielders (Vescovi, 2012), which would explain their faster 20 and $40 \mathrm{~m}$ sprint times. Similar findings have been observed in elite male players, where strikers performed better when compared to other playing positions (Haugen et al., 2012; Sporis et al., 2009). The ability to cover short linear distance faster than an opponent would be advantageous, improving player's (particularly a striker's) goal scoring opportunities (Faude et al., 2012; Reilly et al., 2000). The mean sprint times of the South African outfield positions over $10 \mathrm{~m}$ (1.85 s), $20 \mathrm{~m}$ (3.22 s) and $40 \mathrm{~m}(5.81 \mathrm{~s})$ are slightly slower than of elite Norwegian female soccer players reported by Andersson et al. (2008) (20 m: $3.05 \mathrm{~s})$ and Haugen et al. (2012) $(10 \mathrm{~m}: 1.67 \mathrm{~s} ; 20 \mathrm{~m}: 3.05 \mathrm{~s}$ and $40 \mathrm{~m}$ : $5.64 \mathrm{~s})$. There are two possible reasons for these differences. Firstly, the variations in starting protocols may limit comparisons. Specifically, the current study placed the participants $15 \mathrm{~cm}$ behind the first (starting) beam. In the two aforementioned studies using similar sprint test distances, participants may have had an advantage due to their location at the start of the sprints. For example, Andersson et al. (2008) placed their participants $88 \mathrm{~cm}$ behind a mechanical switch, and participants in the study of Haugen et al. (2012) activated the timer when their front foot stepped of the start pad. Secondly, the slower sprint times may also be related to different training methods in Africa compared to Europe. There is anecdotal evidence that coaches in South Africa tend to be more focused on aerobic rather than anaerobic components of physical conditioning. Implementing specific sprint training for each position may improve the sprinting ability of South African female soccer players.

\section{Upper body muscle endurance}

Defenders showed greater muscle endurance than goalkeepers. With the duties the goalkeepers need to perform (i.e. many throwing and pushing actions), it was expected that they would have performed significantly better than infield positions. However, defenders were significantly lighter than goalkeepers, and their ability to perform more push-ups might be reflective of a better strength-to-body weight 
ratio. Comparing the data to normative values of the adult general population, the mean push-up repetitions for the national female soccer players are ranked between the 70th and 80th percentiles (Moir, 2012).

\section{Intermittent running capacity}

The intermittent running capacity of the study sample was similar across playing positions. This supports the findings of Ingebrigsten et al. (2011) who observed no differences between playing positions and maximal aerobic power (measured through direct methods) in elite female soccer players. Similarly, Haugen et al. (2014) observed no differences between outfield positions in elite Norwegian female players. In contrast, Bradley et al. (2014) found that wide midfielders ran further in a similar endurance test, the Yo-Yo IR1 than central defenders and strikers. Similarly, in male soccer players, studies typically show that midfielders perform significantly better in aerobic fitness tests (Mohr et al., 2003; Sporis et al., 2009). Midfielders are reported to run further than any other playing positions during a soccer game, and therefore it was expected that they would achieve greater distances in the Yo-Yo IR1 in the current study. It is likely that all positions in elite female soccer require a relatively high aerobic and intermittent running capacity due to the strong relationship between Yo-Yo IR1 performance and physical capacity (Krustrup et al., 2005). However, goalkeepers tended to have the lowest values for the Yo-Yo IR1 $(887 \pm 325 \mathrm{~m})$ which could be attributed to their positional role characterized by short, irregular bursts of energy throughout a match (Clark, 2007). The distances achieved by the South African outfield players in the Yo-Yo IR1 test (mean: $1098 \mathrm{~m} \pm$ ) were less than those of national female players from European nations, where distances of $1224 \mathrm{~m}$ (Mujika et al., 2009) and $1379 \mathrm{~m}$ (Krustrup et al., 2005) have been reported. A possible reason for the lower average distances reported in our study could be due to a number of players having travelled from clubs based at sea level to perform testing at an altitude of $1750 \mathrm{~m}$, thus increasing the detrimental effect of relative hypoxia on performance. The altitude factor may have accounted for approximately $5 \%$ of the drop in performance (Kenney et al., 2012). Therefore our findings indicate that the endurance capacity of the national squad should be developed, which may result in more successful performances during international matches (Wisløff et al., 1998).

This study had some limitations. Firstly, training practices of the individual clubs were not documented and we therefore assume that the relative homogeneity in the anthropometric and motor characteristics between the various playing positions was due to similar training methods. Players typically train at their respective clubs before being selected to the national squad's training camp. Therefore, the training practices of each club should be explored further to make more accurate inferences regarding the lack of heterogeneity in some of the study's outcomes. Secondly, relative hypoxia due to testing at altitude (1 $750 \mathrm{~m}$ asl) may have had a detrimental effect on players based at sea level clubs. As mentioned above, this may have caused a decrement in Yo-Yo IR1 performance of around five percent, as athletes rely heavily on their oxidative energy system for aerobic performance.

\section{Conclusion}

The study highlights that anthropometry and certain motor characteristics do not differ by playing positions, a finding which is observed in female soccer players in Europe and other developed nations. A key finding is the importance of sprinting speed in attacking and defensive positions which is similar in elite male soccer players. Additionally, there is a concern over the low intermittent running performances of the national female outfielders as this motor characteristic can influence match success. However, the similarity of certain anthropometric and motor characteristics across playing positions may suggest that fitness coaches train players similarly irrespective of their role on the field. The authors suggest that South African fitness professionals, particularly at club level develop physical conditioning programs specific to each field position in order for players to be more competitive and successful at international level. Fitness assessments should occur on a continuous basis and comparisons should be made with existing normative data in order to guide the development of players over the course of their careers. 


\section{Acknowledgements}

We acknowledge Ms. Tasneem Khan, Ms. Natalia Neophytou and Mr. Ashton Turner, Mr. Luke Stegmann and Ms. Trevlynn Unterhorst for their assistance during data collection.

\section{References}

Andersson H. Neuromuscular fatigue and recovery in elite female soccer: Effects of active recovery. Med Sci Sports Exerc, 2008; 40(2): 372-380

Bradley PS, Bendiksen M, Dellal A, Mohr M, Wilkie A, Datson N, Orntoft C, Zebis M, Gomez-Diaz A, Bangsbo J, Krustrup P. The application of the Yo-Yo intermittent endurance level 2 test to elite female soccer populations. Scand J Med Sci Sports, 2014; 24: 43-54

Castagna C, Castellini E. Vertical jump performance in Italian male and female national-teams soccer players. J Strength Cond Res, 2013; 27(4): 1156-1161

Clark JR. Positional assessment and physical fitness characteristics of male professional soccer players in South Africa. AJPHERD, 2007; 13(4): 453-464

Datson N, Hulton A, Andersson H, Lewis T, Weston M, Drust B, Gregson W. Applied physiology of female soccer: an update. Sports Med, 2014; 44(9): 1225-1240

Davidson A, Trewartha G. Understanding the physiological demands of netball:A time-motion investigation. Int J Perform Anal Spor, 2008; 8(3): 1-17

Faude $\mathrm{O}$, Koch T, Meyer T. Straight sprinting is the most frequent action in goal situations in professional football. J Sports Sci, 2012; 30(7): 625-631

Gabbett TJ. Physiological and anthropometric characteristics of elite women rugby league players. J Strength Cond Res, 2007; 21(3): 875-881.

Garrido-Chamorro R, Sirvent-Belando JE, Gonzalez-Lorenzo M, Blasco-Lafarga C, Roche E. Skinfold sum: Reference values for top athletes. Int J Morphol, 2012; 30(3): 803-809

Harman E. Principles of test selection and administration. In Baechle TR, Earle RW (Eds.), Essentials of Strength Training and Conditioning $3^{\text {rd }} e d$. United States: Human Kinetics, 238-292; 2008

Haugen TA, Tonnessen E, Seiler S. Speed and countermovement-jump characteristics of elite female soccer players, 1995-2010. Int J Sports Physiol Perform, 2012; 7: 340-349

Hoff J. Training and testing physical capacities for elite soccer players. J Sports Sci, 2005; 23(6): 573-582

Ingebrigtsen J, Dillern T, Shalfawi SAI. Aerobic capacities and anthropometric characteristics of elite female soccer players. J Strength Cond Res, 2011; 25(12): 3352-3357

Kenney WL, Wilmore JH, Costill DL. Exercise at altitude Physiology of Sport and Exercise, $5^{\text {th }} \mathrm{ed}$. Champaign, IL: Human Kinetics, 309-329; 2012

Krustrup P, Mohr M, Amstrup T, Rysgaard T, Johansen J, Steensberg A, Pedersen PK, Bangsbo J. The Yo-Yo Intermittent Recovery Test: Physiological response, reliability, and validity. Med Sci Sports Exerc, 2003; 35(4): 697-705

Krustrup P, Mohr M, Ellingsgaard H, Bangsbo J. Physical demands during an elite female soccer game: Importance of training status. Med Sci Sports Exerc, 2005; 37(7): 1242-1248

Manson SA, Brughelli M, Harris NK. Physiological characteristics of international female soccer players. J Strength Cond Res, 2014; 28(2): 308-318

Markovic G, Dizdar D, Jukic I, Cardinale M. Reliability and factorial validity of squat and countermovement jump tests. J Strength Cond Res, 2004; 18(3): 551-555

Martínez-Lagunas V, Niessen M, Hartmann U. Women's football: Player characteristics and demands of the game. J Sport Health Sci, 2014; 3(4): 258-272

McFarland IT, Dawes JJ, Elder CL, Lockie RG. Relationship of two vertical jumping tests to sprint and change of direction speed among male and female collegiate soccer players. Sports, 2016; 4(11) 
McLellan CP, Lovell DI, Gass GC. The role of rate of force development on vertical jump performance. $J$ Strength Cond Res, 2011; 25(2): 379-385

Milanovic Z, Sporis G, Trajkovic N. Differences in body composite and physical match performance in female soccer players according to team position. Paper presented at the 6th INSHS International Christmas Sport Scientific Conference, Szombathely, Hungary; 2012

Mohr M, Krustrup P, Bangsbo J. Match performance of high-standard soccer players with special reference to development of fatigue. J Sports Sci, 2003; 21: 519-528

Moir GL. Muscular endurance. In Miller T (Ed.), NSCA's Guide to Tests and Assessments, Champaign, IL: Human Kinetics, 193-216; 2012

Mujika I, Santisteban J, Impellizzeri FM, Castagna C. Fitness determinants of success in men's and woman's football. J Sports Sci, 2009; 27(2): 107-114

Ohya T, Asami K, Miyazaki Y, Iwai Y, Hirai H, Ikeda T. Anthropometric and Physiological Characteristics of Japanese Elite Women's Rugby Sevens Players. Football Science, 2015; 12: 84-90

Reilly T, Bangsbo J, Franks A. Anthropometric and physiological predispositions for elite soccer. J Sports Sci, 2000; 18: 669-683

Santos DA, Dawson JA, Matias CN, Rocha PM, Minderico CS, Allison DB, Sardinha LB, Silva AM. Reference values for body composition and anthropometric measurements in athletes. PLoS One, 2014; 9(5): e97846

Sedano S, Vaeyens R, Philippaerts RM, Redondo JC, Cuadrado G. Anthropometric and anaerobic fitness profile of elite and non-elite female soccer players. J Sports Med Phys Fit, 2009; 49: 387-394

Sporis G, Canaki M, Barisic V. Morphological differences of elite Croatian female soccer players according to team position. Hrvat. Sportskomed. Vjesn, 2007; 22: 91-96

Sporis G, Jukic I, Ostojic SM, Milanovic D. Fitness profiling in soccer: physical and physiologic characteristics of elite players. J Strength Cond Res, 2009; 23(7): 1947-1953

Stolen T, Chamari K, Castagna C, Wisloff U. Physiology of Soccer: An update. Sports Med, 2005; 35(6): 501536

Thompson WR, Gordon NF, Pescatello LS. Health-related physical fitness testing and interpretation ACSM's Guidelines for Exercise Testing and Prescription, $8^{\text {th }}$ ed., Baltimore, MD: Wolters Kluwer/Lippincott Williams \& Wilkins, 60-102; 2010

Vescovi JD. Sprint profile of professional female soccer players during competitive matches: Female Athletes in Motion (FAiM) study. J Sports Sci, 2012; 30(12): 1259-1265

Wisloff U, Castagna C, Helgerud J, Jones R, Hoff J. Strong correlation of maximal squat strength with sprint performance and vertical height jump in elite soccer players. Br J Sports Med, 2004; 38: 285-288

Wisløff U, Helgerud J, Hoff J. Strength and endurance of elite soccer players. Med Sci Sports Exerc, 1998; 30(3): $462-467$

\section{Corresponding author:}

\section{Philippe Jean-Luc Gradidge, PhD}

Centre for Exercise Science and Sports Medicine (CESSM), School of Therapeutic Sciences, Faculty of Health Sciences, University of the Witwatersrand, Johannesburg, South Africa

Postal address: Centre for Exercise Science and Sports Medicine, Wits Medical School,

Johannesburg, South Africa, 2050

Email address: philippe.gradidge@wits.ac.za 